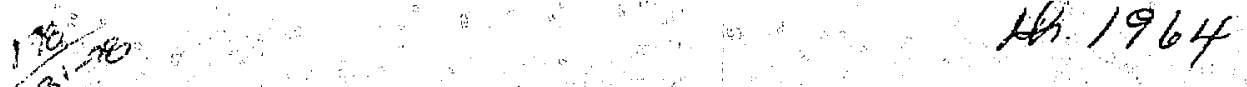

UCRL-52406

is

\title{
REDUCTION OF WEIGHING ERRORS CAUSED BY TRITIUM DECAY HEATING
}

\section{MASTP:}

Janwary 10, 1970

Work performed under tha auspices of the U.S. Departmert of

Energy by the UCLLL under contract number W-7405-ENG-4B.
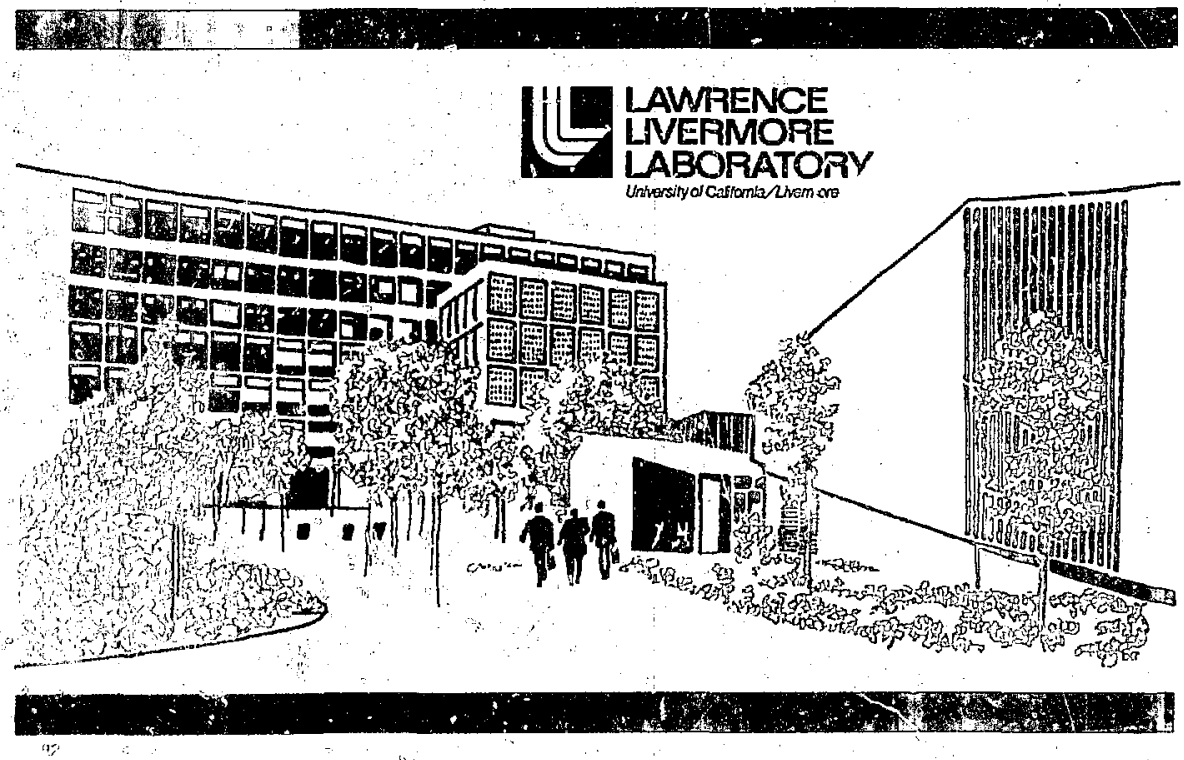


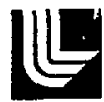

\title{
LAWRENCE UVERMORE LABORATOAY
}

Lniversity ol Caltonia/Livermore, Calfornit, $\$ 4560$

UCRL-52406

\section{REDUCTION OF WEIGHING ERRORS CAUSED BY TRITIUM DECAY HEATING}

\author{
James F. Shaw
}

MS date: January 10,1978

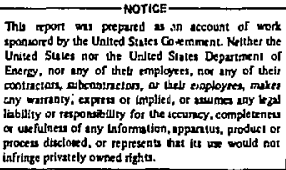

infrlage petwately owned rights. 


\section{CONTENTS}

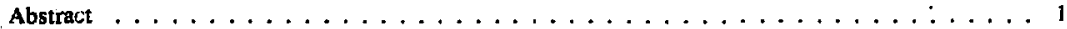

Determining the Weighing Error $\ldots \ldots \ldots \ldots \ldots \ldots \ldots \ldots \ldots \ldots$

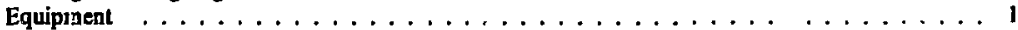

Procedure ..........................

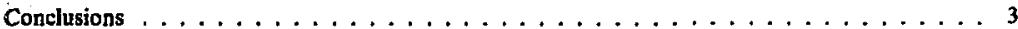

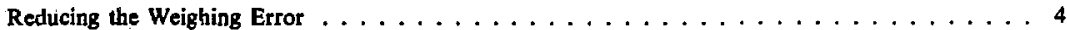

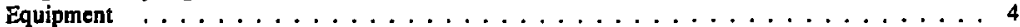

Simulated Tritiun Loading . . . . . . . . . . . . . . . . 4

Actual Tritium Loading $\ldots \ldots \ldots \ldots \ldots \ldots \ldots \ldots \ldots \ldots$

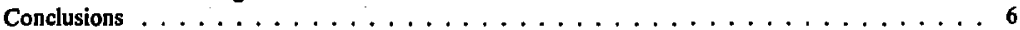




\title{
REDUCTION OF WEIGHING ERRORS CAUSED BY TRITIUM DECAY HEATING
}

\begin{abstract}
The deuterium-tritium source gas mixture for laser targets is formulated by weight. Experiments show that the maximum weighing error ce 1 sed by tritium decay heating is $0.2 \%$ for $\approx 104-\mathrm{cm}^{3} \mathrm{mix}$ vessel. Air cooling the vessel reduces the weighing error by $90 \%$.
\end{abstract}

\section{DETERMINING THE WEIGHING ERROR}

In this study I determined the magnitude of the apparent weight loss when weighing heated pressure vessels, and I investigated a means of reducing the weight loss. A study of this type is recessarily empirical, since there are many variables and we can control only a few. Container shape and surface area influence both the temperature increase and the apparent weight loss. To show this, I experimented with two types of pressure vessels: one with a small length-to-diameter ratio and one with a large ratio. I used electricity rather than tritium as a heat source until the very end of the cooling studies. Electrical heating made it easy to change the effective tritium amount, although it caused a difference in the spatial temperature distribution.

During th:e experiments, I measured the temperature increase above ambient attained by each container at several simulated tritium loads. To determine the temperature drop during weighing, I measured the cooling rate. After analyzing the preliminary data, I measured the apparent weight of each container at several simulated loads.

\section{Equipment}

The equipment included a Voland* $25-\mathrm{kg}$ balance with an A-500 electronic null indicator. Table 1 shows the balance performance measurements.

The first pressure vessel was a 316 stainless steel cylinder $229 \mathrm{~mm}$ long with an outside diameter (o.d.) of $102 \mathrm{~mm}$ and an inside diameter (i.d.) of 25 $\mathrm{mm}$. The overall surface area of the cylinder, including attachments at both ends but excluding the mounting fixture, was approximately $0.0994 \mathrm{~m}^{2}$,

\footnotetext{
- Reference to a company or product name does not imply approval or recommendation of the product by the University of Caliornia or the U.S. Department of Energy to the exclusion of others that may be suitable.
}

and the volume was $104 \mathrm{~cm}^{3}$. A $600-\Omega$ resistance heater was introduced into the vessel by means of an O-ring-seated, threaded flange (see Fig. 1). This heater occupied $80 \%$ of the length of the vessel interior. A glassbeaded electrical feedthrough enabled the vessel to maintain a vacuum (Fig. 2). The vessel was evacuated and backfilled to I atm of helium-4.

The second pressure vessel was a 316 stainless steel coiled tube $9.4 \mathrm{~m}$ long with an $0 . d$. of $14 \mathrm{~mm}$, an i.d. of $7 \mathrm{~mm}$, a surface area (excluding the mounting fixture) of $0.411 \mathrm{~m}^{2}$, and a volume of $400 \mathrm{~cm}^{3}$. Both ends had been cut off and replaced with an electrical feedthrough (Fig. 3). Heater resistance was $418 \Omega$.

Copper/copper constantan thermocouples were used to monitor the experiments. The contacts were parallel and were made intrinsic by means of spotwelding to the vessel wall. The reference thermocouple was intrinsic to a $10-\mathrm{k}_{\mathrm{B}}$ block of stainless steel. A six-place digital voltmeter provided readout of the thermocouples. Two power sources provided $100 \mathrm{~V}$ of controlled direct current to the heater.

\section{Procedure}

Vessels were heated electrically with a controlled direct current. Heater resistances (R) equaled $609 \Omega$

Table 1. Balance performance.

\begin{tabular}{rcc}
\hline Range, kg & Sensitivily, mg & Repertability, mg \\
\hline 0 & & \\
5 & 1.4 & 0.2 \\
10 & 1.4 & 1.2 \\
15 & 1.4 & 3.0 \\
20 & 1.4 & 1.4 \\
\hline
\end{tabular}

Class 5 weights were used. 


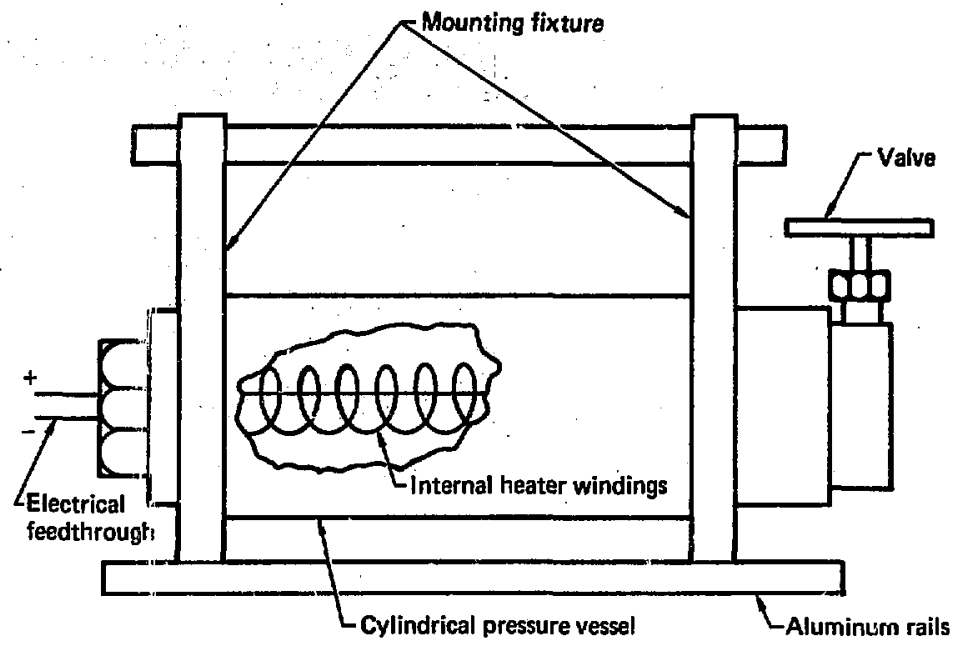

Fi. 1. 104-w' cylladical presoure reasel.

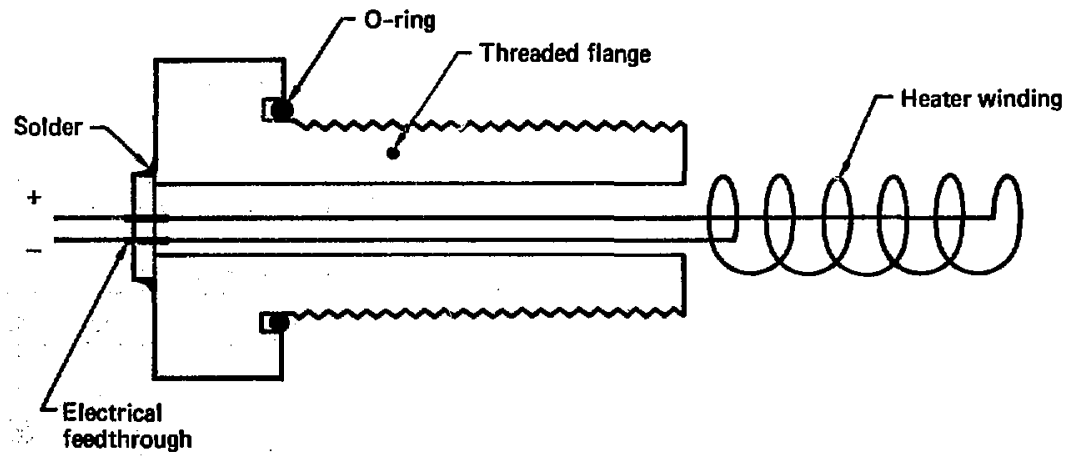

Fig. 2. Electrical benter for cylodical presure resaed. 


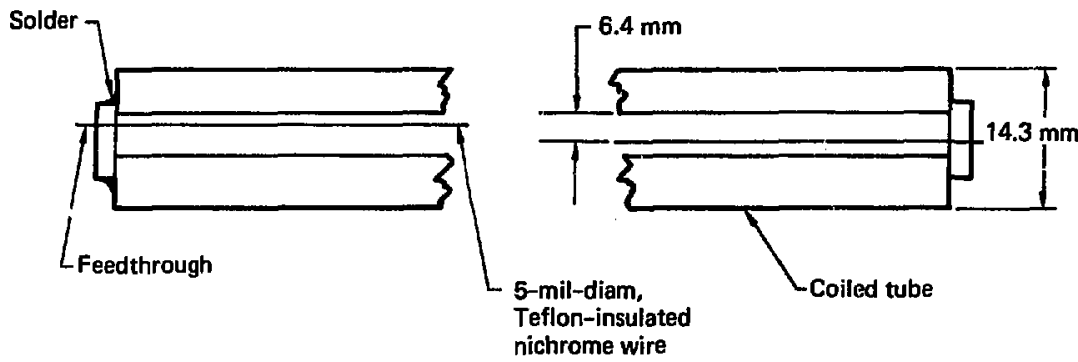

Fig. 3. 400 -em ${ }^{3}$ coll presaure resel.

for the cylinder and $418 \Omega$ for the coil. The voltage used (E) is given by

$$
E=\sqrt{\left(g_{2}\right)(0.324 W / g)(r)}
$$

where

$$
\begin{aligned}
g T_{2} & =\text { grams of tritium, } \\
W / g & =\text { watts per gram of tritium, } \\
\mathbf{r} & =\text { resistance in obms. }
\end{aligned}
$$

Temperature increments were obtained for the heat equivalent of $1.4,2.0,2.5,3.5$, and $5.0 \mathrm{mnol}$ of tritium-2. Cooling rates for $3 \mathrm{~min}$ showed no loss greater than $0.2 \mathrm{~K}$. After removing the thermocouples, I heated the vessel at a preselected voltage equivalent to the desired tritium concentration. Equilibrium periods were $5 \mathrm{~h}$ for thes cylinder and $2 \mathrm{j} / 2 \mathrm{~h}$ for the coil. Before weighing each vessel I kept it at a level temperature overnight to be certain that equilibrium had been established.

Working quickly, I disconnected the power leads and placed the vessel on the balance pan. A built-in spirit level on the pan showed when the vessel was positioned properly. Balance weights were not removed from these pans between weighings. After recording the rest point, I shifted the rider $10 \mathrm{mg}$ to determine the balance sensitivity. Then I found and recorded a new rest point. Next. I removed the vessel from the balance and reconnected the power leads to the vessel. It took less than 3 min to disconnect the leads, weigh the vessel, and reconnect the leads to the vessel. The vessel was seheated for at least 15 min between weighings. A minimum of ten succes- sje wejghings were made at each tritium concentration. Two tares were taken, one before and one after the series of tritium weighings.

\section{Conclusions}

The sesults of my measurements are summarised in Figs. 4 and 5. In Fig. 4, the temperature above ambient is plotted with respect to the simulated tritium load. A straight line has been drawn through the set of points for each vesiol. At a given heat input, the temperature increase in ihe coil yessel is about I K lower than in the cylinder. This difference is expected, since the coil vessel has over four times the surface area of the cylindrical vessel.

The temperature increnents were measured while the vessels were on the table and some air was moving due to the room air conditioning. Different conditions of air flow would change the results. The results show the relative effects of loading on these vessels and indicate the magnitude of the temperature increase.

Apparent weight loss vs tritium load is plotted in Fig. 5. The temperature decrease during weighing was small, so the curves are not adjusted for this effect. The weight loss for the coil is almost twice that of the cylinder.

Based on these data, the weight loss correction is a maximum of $0.3 \%$ for the coil and a maximum of $0.2 \%$ for the cylinder. This error is so large that a correction must be used for accurate work. An alternative would be to force air-cool a tritiumloaded vessel before weighing to minimize the temperature above the ambient and thus the weight loss. 


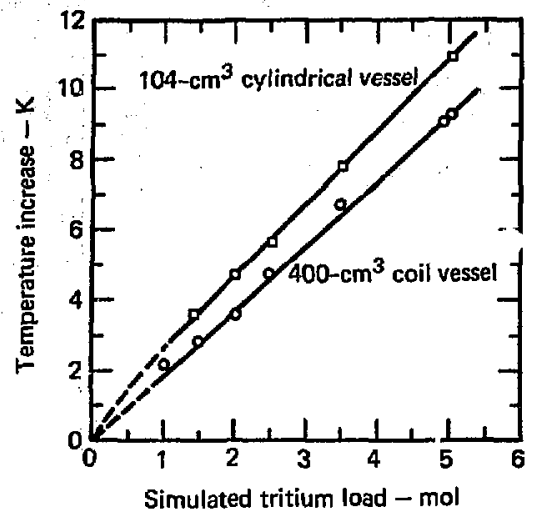

Fig. 4. Temperature above ambient as a function of simulated iritium lond.

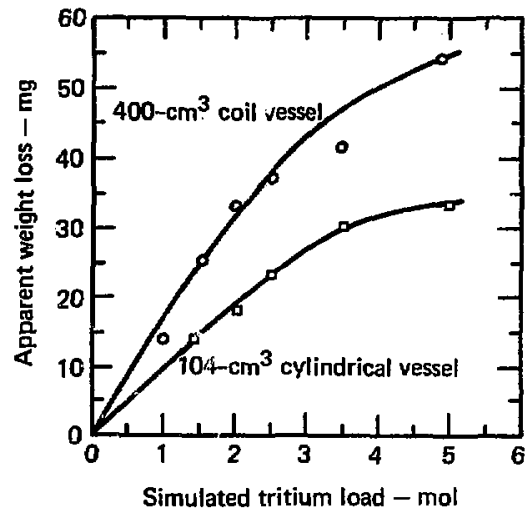

Fig. 5. Apparent weight loss as a function of simulated trltium losd.

\section{REDUCING THE WEIGHING ERROR}

In the first part of this paper I have shown that a vessel treated by tritium decay can have an apparent weight loss as high as $40 \mathrm{mg}$. Here I show that forced air-cooling a tritium-loaded vessel to near the ambient temperature in the balance room is a practical way to eliminate must of these weigint losses and, equally important, to reduce weighing errors considerably. This method obviates a corrective factor. Forced room air sools less efficiently than a liquid hent-transfer rnedium, and, unlike chilled air, it cannot eliminate remperature increases entirely. These disadvantages are offset by its cleanliness and ease of application, however.

\section{Equipment}

The air-cooling apparatus is a stainless steel tube $71 \mathrm{~cm}$ long with an o.d. of $20.635 \mathrm{~cm}$ and an i.d. of $20 \mathrm{~cm}$. A Rotron vane fan is bolted to one end. The entire assembly is bolted in a horizontal position to a large table in our balance room. A Teflon mat lines the cooling chamber floor to prevent scuffing the aluminum support rails on the vessel whenever it is slid in and out. The electronic measuring equipment, power supplies, electrically heated vessels, and thermocouples are the same as were used during the weight loss studies. For these cooling studies, i used a $200-\mathrm{cm}^{3}$ cylindrical pressure vessel loaded with $2.88 \mathrm{~mol}$ tritium and a new thermocouple for the ressel. Instead of being spotwelded to the vessel surface, the junction was inserted into a thermowell in the vessel wall.

\section{Simulated Tritium Loading}

To determine the effectiveness of the cooling chamber, I again heated the two pressure vessels to preselected tritium concentrations. When temperature equilibrium was reached and with the vessel's electrical power still on, I placed the vessel in. side the cooling chamber, turned or the fan, and recorded temperature vs time. Average air velocities measured at the chamber exit were:

- $104-\mathrm{cm}^{3} \mathrm{cylindrical}$ vessel, 60 liters/s;

- $200 \cdot \mathrm{cm}^{3}$ cylindrical vessel filled with tritium, 56 liters/s;

- $400-\mathrm{cm}^{3}$ coil yessel, 70 liters $/ \mathrm{s}$.

Once the vessel had cooled to its lowest temperature increase, I removed it from the chamber and measured its reheating rate while the vessel was on the balance pan and the balance case door was shut. Since no weighings were to be made, the balance beam was left in its arrested position. For uniformity between measurements, zero time and the biseline temperatures are those recorded the moment before the vessel was removed from the cooling chamber. This explains the slight shift in the slope at the start of the warming rate curve. The time spent to carry the vessel from the chamber and place it on the balance pan varied from 1 to 1 1/2 min. 


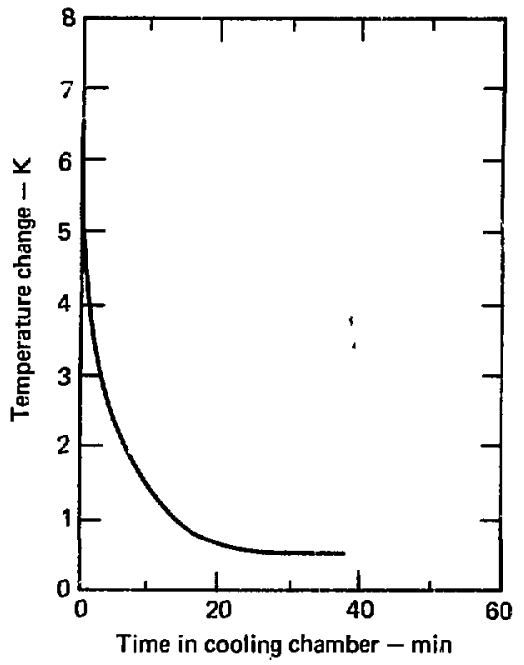

Fig. 6. Cooling rate for $400-\mathrm{cm}^{3}$ coll vessel. Simulated tritium Joad $=5 \mathrm{~mol}$. Cooling air fow $=150 \mathrm{st}^{3} / \mathrm{min}$.

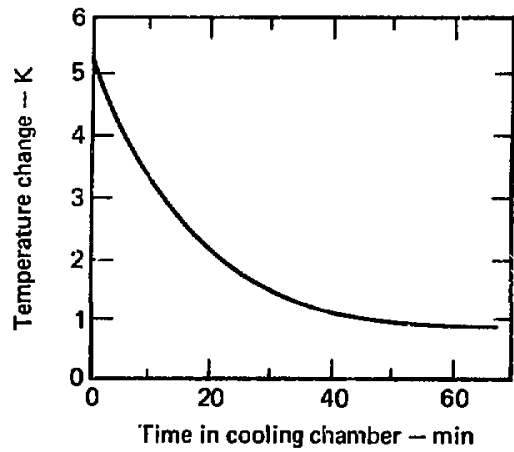

Fig. 7. Cooling rate for $104-\mathrm{em}^{3}$ cyllindrical ressel. Simuluted tritium load $=2.5 \mathrm{~mol}$. Cooling afr now $=130 \mathrm{ft}^{3} / \mathrm{min}$.

The 104-cm ${ }^{3}$ cylindrical vessel was heated to a simulated tritium concentration of $2.5 \mathrm{~mol}$, equivalent to the maximum allowable working pressure of the vessel. The voltage available from the regulated direct current power supply determined the size of the simulated tritium loading of the coil vess.l, 4.0 and $5.0 \mathrm{~mol}$.

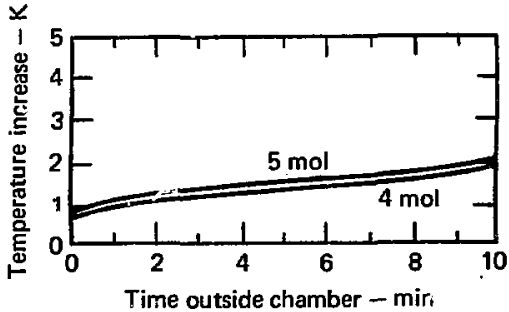

Fig. 8. Rebeating rate for $400 \mathrm{~cm}^{3}$ coil vessel. Simalnted tritinn lond $=4$ and 5 mol.

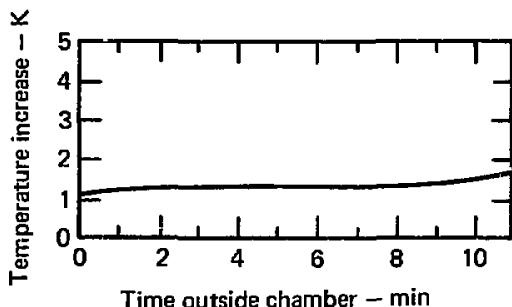

Fig. 9. Reheating rate for $104-\mathrm{cm}^{3}$ cyllindrical vessel. Simulnted tritium load $=2.5$ mol,

Cooling rate curves show that the electrically heated vessels can be cooled to a temperature increase of $2^{\circ} \mathrm{C}$ or less (Figs. 6 and 7). The coil vessel with its greater surface area can be cooled to a temperature slightly less than $1^{\circ} \mathrm{C}$ above the original temperature (Fig. 6), whereas the 104-cm ${ }^{3}$ cylinder can be cooled to a temperature slightly more than $1^{\circ} \mathrm{C}$ above the original (Fig. 7). The lower mass, higher loading, and larger surface area of the coil vessel allow it to warm on the balanze faster than the thick-walled cylindrical vessel (see Figs. 5 and 6). Since a reasonably accurate weighing takes less than $5 \mathrm{~min}$, the temperature remains within $1.5^{\circ} \mathrm{C}$ of the original during weighings and the weight error is less than $0.1 \%$ (Figs. 8 and 9 ).

\section{Actual Tritium Loading}

The procedure for studying the $200-\mathrm{cm}^{3}$ source vessel loaded with $2.88 \mathrm{~mol}$ tritium was somewhat different from that used to study the electrically heatej vessel. After it was warmed to some equi:ibrium temperature (Fig. 10), 1 placed the source vessel on the balance pan and made five consecutive 


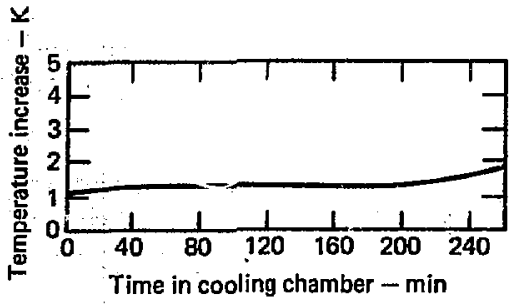

Fig. 10. Rehenting rate for $200-\mathrm{eas}^{3}$ cylindrical vescel. Actual tritsim load $=2.9 \mathrm{~mol}$

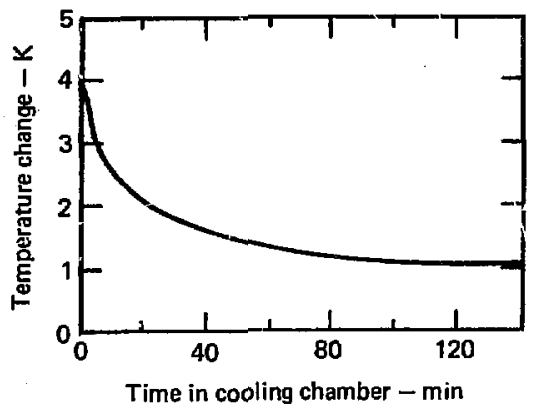

Fig. 11. Cooling rate for $200-\mathrm{cm}^{3}$ cylindrical ressel. Actual tritfun lond = $2.9 \mathrm{~mol}$. Cooling air flow $=120 \mathrm{ft}^{3} / \mathrm{min}$

weighings. The average of these five was used as the gross weight. Next I removed the vessel from the balance and placed it inside the cooling chamber. Once the vessel bad reached its minimum temperature (Fig, 11), I removed it from the cooling chamber, placed it on the balance pan, and reweighed it. The average of five consecutive weighings was the tare from which I calculaied the reported weight shifts (Fig. 12).

Equilibrium temperatures ranging from $3107^{\circ} \mathrm{C}$ were obtained by allowing the vessel to equilibrate under various laboratory storage conditions- - an a work bench, in a fums hood, and inside the balance case itself. The weight shifts in Fig. 10 confirm those I found during the earlier part of this study, using electrically simulated tritium decay heat. This part of the study shows that applying a corrective factor would be difficult because the equilibrium temperature depends so strongly on the storage conditions.

In Fig. 10, the plo: of apparerit weight loss vs temperature change, the scatter tietween the tares taken on the warm vessel has a staitdard deviation

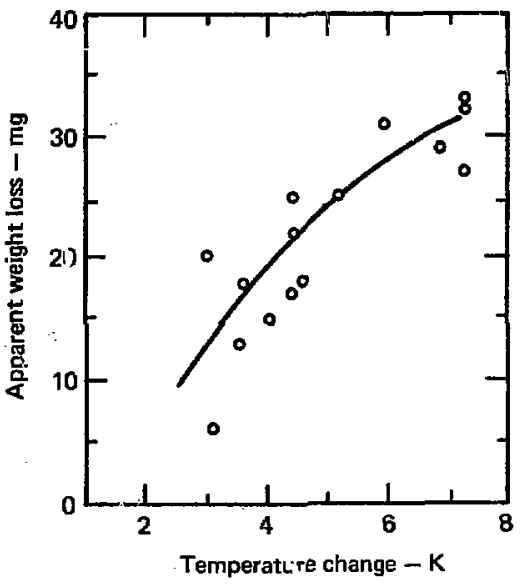

17g. 12. Measured weight loss for $200-\mathrm{cm}^{3}$ cylindrical vessel. Actuni stitiun loed $=\mathbf{2 . 9} \mathrm{mol}$.

of $\pm 14 \mathrm{mg}$. Not shown in this figure, since the $Y$, axis points were derived from the difference between the warm mass and the cool mass, are the tares taken on the vessel after it was cooled. These hid a standard deviation of $\pm 7 \mathrm{mg}$. Yet the repeatability of the balance in the $20 \mathrm{~kg}$ weight range is approximately $3 \mathrm{mg}$.

To find some clear reason for this descrepancy, I again air-cooled the vessel several times and measured its minimum temperature equilibrium by a potentiometer more sensitive than the one used earlier. Here I found that, for the same cooling period, the minimum temperature the vessel reached varied by $\pm 0.15^{\circ} \mathrm{C}$. This scatter is characteristic of the couling method itself, more than likely coming from temperature variations in the air that enters the cooling chamber and changes in the fan motor's speed due to line voltage fluctuations. Cooling to a uniform tempesature before each weighing reduced the deviation from $\pm 7 \mathrm{mg}$ to $\pm 4 \mathrm{mg}$.

\section{Conclusions}

Cooling the vessel before weighing has two positive, related efiects:

- The negative weight shift is all but eliminated,

- The veighing eror band is narrowed close to that which is normal for the balance (measured as $\pm 3 \mathrm{mg}$ ). 
The significance of this error reduction can better be seen in a gas loading where the amount of tritium approximates a real life, situation. Thus, when the tritium loading is $20 \mathrm{~g}$ and the temperature increase for the vessel is $5^{\circ} \mathrm{C}$, the mean weighing ertor for ihe warm vessel is $0.125 \%$. However, after being cooled to near $1^{\circ} \mathrm{C}$ above the original temperature, the same vessel has a mean weighing error of $0.025 \%$. By measuring carefully ihe final temperature incresitent and cooling to this same temperature before each weighing, the error can be reduced a bit more-to $0.020 \%$. 